Article

\title{
Study on the Adsorption Behavior between an Imidazolium Ionic Liquid and Na-Montmorillonite
}

\author{
Jingjing Pei ${ }^{1}$, Xuesong Xing ${ }^{2}$, Boru Xia ${ }^{1,3}$, Ziming Wang ${ }^{1,3}$ and Zhihua Luo ${ }^{1,3, *}$ \\ 1 School of Engineering and Technology, China University of Geosciences, Beijing 100083, China; \\ peijj@cugb.edu.cn (J.P.); brxia@cugb.edu.cn (B.X.); wangzm1996@163.com (Z.W.) \\ 2 China National Offshore Oil Corporation Research Institute Co., Ltd., Beijing 100028, China; \\ xingxs@cnooc.com.cn \\ 3 Key Laboratory on Deep GeoDrilling Technology, Ministry of Land and Resources, Beijing 100083, China \\ * Correspondence: luozhihua@cugb.edu.cn; Tel.: +86-010-8232-2624
}

Received: 26 February 2019; Accepted: 5 April 2019; Published: 9 April 2019

check for updates

\begin{abstract}
Interactions between 1-butyl-3-methylimidazolium tetrafluoroborate (IL), an ionic liquid, and Na-montmorillonite (Na-MMT) were studied under different kinetic conditions to investigate the adsorption behavior of IL by Na-MMT. The adsorption of IL by Na-MMT was rapid, with a fast rate, reaching a capacity of $0.43 \mathrm{mmol} / \mathrm{g}$, lower than Na-MMT's cation exchange capacity (CEC) of $0.90 \mathrm{mmol} / \mathrm{g}$. Meanwhile, the highest adsorption rate occurred at the IL concentration of $1000 \mathrm{mg} / \mathrm{L}$. The exchangeable cation of Na-MMT could not be completely substituted by the cation group of IL regardless of the IL concentration. Stoichiometric desorption experiments confirmed that the cation exchange was the dominating adsorption mechanism for the IL adsorption by Na-MMT. The pH value of the solution between 2 and 11 had a negligible effect on the adsorption amount of IL by Na-MMT. The cation group of IL interacted into the interlayer of Na-MMT successfully, resulting in the change in the wettability of Na-MMT. A bilayer formation of the cationic group should occur in the interlayer of the modified Na-MMT and the configuration of IL was dependent on the adsorption amount of IL. Furthermore, the thermal stability of the modified Na-MMT was also dependent on the adsorption amount of IL.
\end{abstract}

Keywords: ionic liquid; adsorption; Na-montmorillonite; high temperature; interaction

\section{Introduction}

Montmorillonite (MMT) is the best-known group of clay minerals with a three-layer structure. Each crystal platelet consists of an octahedral sheet sandwiched between two-sheet silica tetrahedral. There are predominant substitutions of $\mathrm{Al}^{3+}$ for $\mathrm{Si}^{4+}$ in the tetrahedral and $\mathrm{Mg}^{2+}$ for $\mathrm{Al}^{3+}$ in the octahedral, giving montmorillonite negative charge which is balanced by the adsorbed cation (e.g., $\mathrm{Na}^{+}$ and $\mathrm{Ca}^{2+}$ ) [1,2]. Of MMT Na-MMT has been widely used in industry, including the treatment of water pollution, drugs, catalysts, nanometer materials, drilling materials, coatings and so on because of its high specific surface, high cation exchange capacity (CEC), common occurrence, and low cost [3-5]. For example, Na-MMT is added into a variety of polymer matrix in order to improve the strength and thermal stability of the polymer materials while retaining the lightweight property of polymer materials [6,7]. However, the inorganic Na-MMT cannot disperse well in the polymer matrix. Organic cations can easily exchange with the $\mathrm{Na}^{+}$in the interlayer of $\mathrm{Na}-\mathrm{MMT}$ and change the wettability of the clay. Hence, organic compounds are used to modify Na-MMT and enhance dispersion and compatibility of the modified Na-MMT in organic phase [8-10]. The modification of Na-MMT with conventional organic compounds has been extensively investigated for the past several decades. However, the conventional organic compounds such as quaternary ammonium ions start degradation 
from $180^{\circ} \mathrm{C}$ and have the disadvantage of lower thermal stability, limiting its application [11]. In recent years, treatment of the layered clay with ionic liquids may open a new way in higher-temperature application [12,13].

Ionic liquids (ILs) are organic salts which consist of cations and anions. Different from solid inorganic or organic salts, ILs remain liquid state at room temperature. Due to their unique properties such as "zero" vapor pressure, high thermal stability, good solvent properties with organic, inorganic materials, ILs have attracted significant interest and are considered as an alternative to conventional organic compounds for a wide range of industrial applications [14-17]. One important property of ILs is its high thermal stability. Most of ILs remain stable in a liquid state at $300{ }^{\circ} \mathrm{C}$ and some of them remain stable even up to $400^{\circ} \mathrm{C}$. ILs have been used to modify Na-MMT, which can overcome the shortcomings of conventional organic compounds and improve the thermal stability of Na-MMT with polymer materials [18,19]. Livi et al. reported that Na-MMT modified with an imidazolium ionic liquid has excellent thermal stability compared with conventionally treated Na-MMTs [18]. Laurence et al. used a phosphonium ionic liquid to improve the thermal stability of MMT up to $330^{\circ} \mathrm{C}$ [19]. In our previous work, we investigated the influence of an imidazolium ionic liquid on the rheological and filtration performance of water-based drilling fluids at high temperatures. The ionic liquid (abbreviated as IL) with a very low concentration was directly added into drilling fluids and it can improve the performance of drilling fluids at high temperatures up to $240^{\circ} \mathrm{C}$. Hence the ionic liquid has a potential application in deep drilling of petroleum, gas or geothermy [20]. However, these reports mainly focus on the application of the IL-interacted Na-MMT at high temperature rather than the microscopic mechanism of the IL by Na-MMT through the adsorption behavior.

This study mainly focuses on the adsorption behavior of the IL by Na-MMT, including the adsorption kinetics, the adsorption isotherm, the desorption of exchangeable cations and microscopic structure of the interacted IL in the interlayer, in order to further understand the interaction mechanism between the IL and Na-MMT.

\section{Results and Discussion}

\subsection{IL Adsorption Kinetics}

The study was aimed to investigate the needed time to reach adsorption equilibrium so that the adsorption equilibrium can be established at a fixed time in a further study. The adsorption of IL by Na-MMT was quick, maybe instantaneous (Figure 1a), similar to some cation adsorption [21]. The maximal adsorbed amount of $0.436 \mathrm{mmol} / \mathrm{g}$ at $30 \mathrm{~min}$, had basically no change from the adsorbed amounts of $0.429 \mathrm{mmol} / \mathrm{g}$ at $5 \mathrm{~min}$. The rapid adsorption of IL by Na-MMT suggested the ionic liquid had a great affinity for Na-MMT surfaces. Na-MMT provided a great advantage due to its high cation exchange capacity (mainly $\mathrm{Na}^{+}$) for the cationic group of IL. The adsorption equilibrium would be established at least after $1 \mathrm{~h}$ of contact with Na-MMT in the further study.
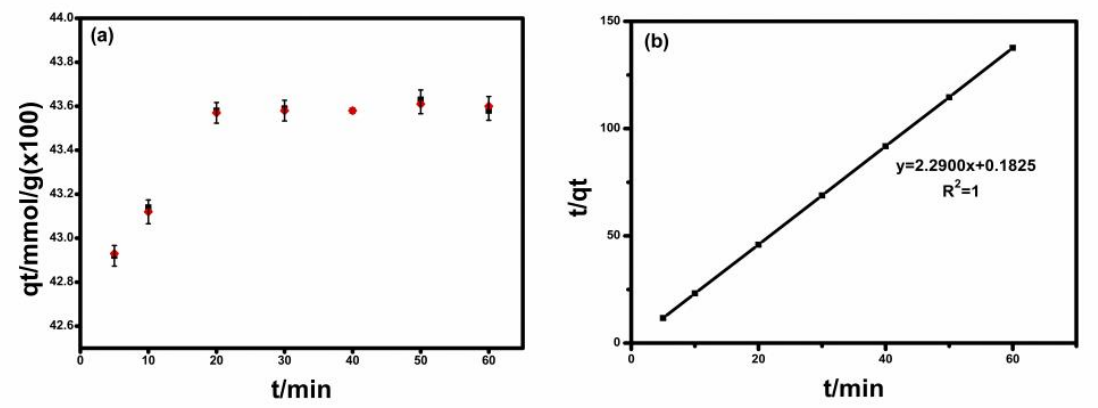

Figure 1. (a) Influence of time on the adsorbed amount of the ionic liquid (IL)IL. (b) $t / q_{t}$ at different times and the fitted plot. 
Several kinetic models were fitted to the experimental data and only the pseudo-second-order model can describe well the adsorption of IL by Na-MMT. The pseudo-second-order model has the form:

$$
\frac{\mathrm{t}}{\mathrm{q}_{\mathrm{t}}}=\frac{1}{k_{s} q_{e}^{2}}+\frac{1}{q_{e}} t .
$$

The fitted plot was shown in Figure $1 \mathrm{~b}$ and we can see that the adsorption of IL by Na-MMT fitted very well the model with a coefficient of determination $R^{2} 1.0000$. The plot of $t / q_{t}$ vs.t could be used to judge the surface heterogeneity of Na-MMT, and the plot of $t / q_{t} v s . t$ would not be a straight line or divided into two segments if the surface of Na-MMT was heterogeneous [22]. In this study, the plot is a perfectly straight line, showing that the adsorption site of the clay mineral was homogeneous, similar

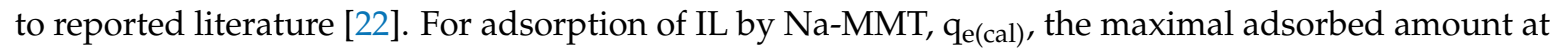
equilibrium time, of $0.43 \mathrm{mmol} / \mathrm{g}$ was obtained by the pseudo-second-order model, equal to $\mathrm{q}_{\mathrm{e}(\exp ) \text {, }}$ the experimental value (Table 1 ).

Table 1. The kinetic parameters obtained by the pseudo-second-order model.

\begin{tabular}{cccc}
\hline $\mathrm{C}_{\mathbf{0}}(\mathrm{mmol} / \mathrm{L})$ & $\mathbf{q}_{\text {e(exp) }}(\mathbf{m m o l} / \mathrm{g})$ & $\mathbf{q}_{\text {e(cal) }}(\mathbf{m m o l} / \mathrm{g})$ & $\mathbf{R}^{\mathbf{2}}$ \\
\hline 4.42 & $0.43 \pm 0.002$ & 0.43 & 1.00 \\
\hline
\end{tabular}

\subsection{IL Adsorption Isotherm}

Based on the kinetics studies, the adsorption time was fixed at $1 \mathrm{~h}$ by which equilibrium would be established to further study. Adsorption amounts versus initial concentrations of IL and adsorption rate versus initial concentration of IL are shown in Figure 2. The adsorption rate $(r)$ is obtained by the following equation:

$$
\mathrm{r}=\left(\mathrm{q}_{\mathrm{e}} \mathrm{M}\right) /\left(\mathrm{C}_{0} \mathrm{~V}\right) * 100 \%
$$

where $\mathrm{q}_{\mathrm{e}}$ is the adsorption amount of IL by Na-MMT at equilibrium $(\mathrm{mmol} / \mathrm{g}), \mathrm{M}$ is the weight of adsorbent $(\mathrm{g}), \mathrm{C}_{0}$ is the initial concentration of IL $(\mathrm{mmol} / \mathrm{L})$ and $\mathrm{V}$ is the volume of the IL solution.
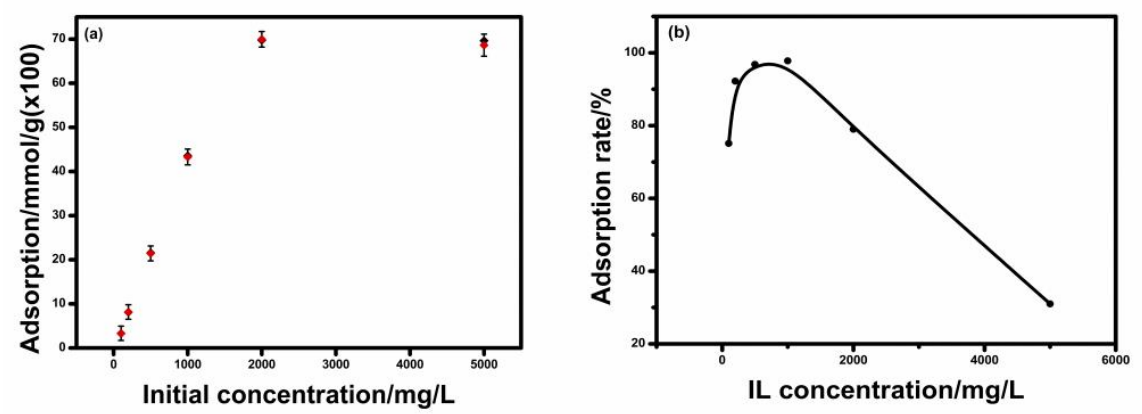

Figure 2. (a) Adsorption amount of IL versus initial concentrations of IL; (b) adsorption rate versus initial concentration of IL.

For the adsorption of IL by Na-MMT, the adsorption amount at equilibrium $\left(\mathrm{q}_{\mathrm{e}}\right)$ firstly increased with the initial concentration of IL (Figure 2a). The value of $\mathrm{q}_{\mathrm{e}}$ is $0.43 \mathrm{mmol} / \mathrm{g}$ at the initial concentration of $1000 \mathrm{mg} / \mathrm{L}$, similar to the result of the kinetics study. The $\mathrm{q}_{\mathrm{e}}$ reached the maximum value of $0.70 \mathrm{mmol} / \mathrm{g}$ at the initial concentration of $2000 \mathrm{mg} / \mathrm{L}$, and then the value of $\mathrm{q}_{\mathrm{e}}$ has a slight decrease at the initial concentration of $5000 \mathrm{mg} / \mathrm{L}$. Meanwhile, the highest adsorption rate (r) of $98.0 \%$ was observed at the initial concentration of $1000 \mathrm{mg} / \mathrm{L}$ (Figure 2b). But when the initial concentration of IL increased to 2000 and $5000 \mathrm{mg} / \mathrm{L}$, the adsorption rate (r) decreased to $78.0 \%$ and $31.0 \%$, respectively. Meanwhile, the CEC value of $0.9 \mathrm{mmol} / \mathrm{g}$ for Na-MMT was larger than the maximum value of 0.70 $\mathrm{mmol} / \mathrm{g}$ at the initial concentration of $2000 \mathrm{mg} / \mathrm{L}$. These results indicated that the cation group of IL could not substitute the whole exchangeable cation of Na-MMT even if the concentration of IL was 
increased. The adsorption capacity of IL by Na-MMT not only depends on the initial concentration of IL but also on the cation exchangeable capacity of Na-MMT, which has been reported in other literature [23]. For the adsorption of IL by Na-MMT, the adsorption rate would not be $100 \%$ and the highest adsorption rate of IL by the clay mineral occurs at $1000 \mathrm{mg} / \mathrm{L}$. This conclusion also provides the basis for the application of IL.

The experimental data were fitted to Langmuir and Freundlich isotherm model, respectively. The Freundlich fit with a coefficient of determination $R^{2} 0.31$ resulted in a big discrepancy between the experimental and calculated data, indicating the adsorption of IL by Na-MMT cannot follow the Freundlich isotherm model. Compared to the Freundlich fit, the better fit to the Langmuir model with a higher coefficient of determination $\mathrm{R}^{2} 0.78$ but the adsorption of IL by Na-MMT cannot follow Langmuir model well, suggested a surface-limited adsorption for the adsorption. The adsorption of other cations by Na-MMT, such as chlorpheniramine and tetracycline also were described by the Langmuir model, similar to the adsorption of IL by Na-MMT $[5,24]$. The configuration of IL in the Na-MMT interlayer may be not monolayer because Langmuir isotherm model is established on the hypothesis of monolayer adsorption of adsorbate by the adsorbent.

Langmuir isotherm can be transformed into a linear form:

$$
\frac{C_{\mathrm{e}}}{\mathrm{q}}=\frac{1}{q_{m}} C_{\mathrm{e}}+\frac{1}{q_{m} \mathrm{~K}_{\mathrm{b}}}
$$

where $\mathrm{C}_{\mathrm{e}}$ is the concentration of IL solution $(\mathrm{mmol} / \mathrm{L})$, $\mathrm{q}$ is the adsorbed amounts of IL at equilibrium $(\mathrm{mmol} / \mathrm{g}), \mathrm{q}_{\mathrm{m}}$ is the maximum adsorption amount $(\mathrm{mmol} / \mathrm{g})$, and $\mathrm{K}_{\mathrm{b}}$ is the Langmuir coefficient $(\mathrm{L} / \mathrm{mmol})$. So that $\mathrm{K}_{\mathrm{b}}$ and $\mathrm{q}_{\mathrm{m}}$ can be obtained by the linear regression in Table 2.

Table 2. The isotherm parameters obtained by fitting the experimental data to the Langmuir isotherm model.

\begin{tabular}{cccc}
\hline $\mathbf{q}_{\mathrm{m}(\mathrm{cal})}(\mathbf{m m o l} / \mathrm{g})$ & $\mathbf{q}_{\mathbf{m}(\mathbf{e x p})}(\mathbf{m m o l} / \mathrm{g})$ & $\mathbf{K}_{\mathbf{b}}(\mathrm{L} / \mathbf{m m o l})$ & $\mathbf{R}^{2}$ \\
\hline 0.83 & $0.70 \pm 0.01$ & 4.60 & 0.78 \\
\hline
\end{tabular}

The fitted $\mathrm{q}_{\mathrm{m}}$ and $\mathrm{K}_{\mathrm{b}}$ values were $0.83 \mathrm{mmol} / \mathrm{g}$ and $4.60 \mathrm{~L} / \mathrm{mmol}$, respectively, comparable to chlorpheniramine adsorption of $0.64 \mathrm{mmol} / \mathrm{g}$ and $10 \mathrm{~L} / \mathrm{mmol}$ by a similar Na-MMT [5,17]. The $\mathrm{K}_{\mathrm{b}}$ can be used to calculate the adsorption free energy $\left(\Delta G^{\circ}\right)$ by the following equation [7]:

$$
\Delta G^{\mathrm{o}}{ }_{a d s}=-R T \ln \left(K_{\mathrm{b}} \times 55.5\right) .
$$

The calculated value of $\Delta \mathrm{G}^{\circ}$ for the adsorption of IL by Na-MMT were $-13.7 \mathrm{~kJ} / \mathrm{mol}$, close to the value of $-15.8 \mathrm{~kJ} / \mathrm{mol}$ for chlorpheniramine adsorption by Na-MMT, higher than that of $-6.2 \mathrm{~kJ} / \mathrm{mol}$ for chlorpheniramine adsorption by talc, further showing that the ionic liquid has a great affinity for Na-MMT surfaces. Na-MMT provides a great advantage due to its high cation exchange capacity for the cationic group of the IL.

\subsection{Cation Desorption Accompanying IL Adsorption}

Figure 3 shows the desorbed cations amounts vs. the adsorption amount of IL. It can be seen that the total desorbed amount increases with the adsorption amount of IL. There was a better linear correlation between the adsorbed amount of IL and total desorbed amounts, indicating that cation exchange adsorption is mainly responsible for the IL adsorption by Na-MMT, similar to the adsorption of other organic compounds on Na-MMT $[17,18]$. The total desorbed amounts of exchangeable cations are about $0.72 \mathrm{mmol} / \mathrm{g}$, lower than the CEC value of the raw Na-MMT, further indicating that the cation group of IL could not substitute the total cation of the clay mineral. Meanwhile, most of the desorbed cations were $\mathrm{Na}^{+}$, confirming that the montmorillonite was the Na-montmorillonite in $\mathrm{Na}$ form. 


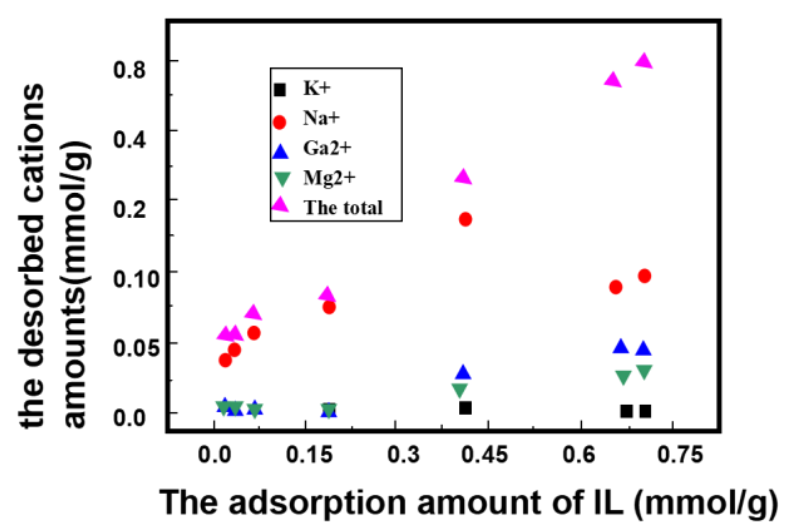

Figure 3. The desorbed amount of cations versus the adsorption amount of IL.

\subsection{Influence of Solution $\mathrm{pH}$ on IL Adsorption}

Figure 4 shows the adsorption amounts of IL by Na-MMT at different solution $\mathrm{pH}$. It was obvious that the adsorption amounts of IL by Na-MMT basically remained at about $0.43 \mathrm{mmol} / \mathrm{g}$ as the solution $\mathrm{pH}$ was increased from 2 to 11 . The adsorbed amounts of IL remained relatively stable in wide $\mathrm{pH}$ ranges tested, indicating that solution $\mathrm{pH}$ had much less effect on the adsorption amounts of IL by Na-MMT, similar to the adsorption of some organic compounds by Na-MMT $[17,18]$. Thus, the steady adsorption amounts of IL between $\mathrm{pH} 2$ and 11 could be attributed to $\mathrm{pH}$-independent cation concentration of IL between $\mathrm{pH} 2$ and 11. However, when solution $\mathrm{pH}$ was increased from 11 to 13 , the adsorption amounts of IL greatly decreased from 0.43 to $0.22 \mathrm{mmol} / \mathrm{g}$. When the $\mathrm{pH}$ value of the dispersion increased to 13, the strong base solution may result in lower zeta potential of Na-MMT. Then, fewer cations may insert into the interlayer of Na-MMT with lower zeta potential. That is to say, less amount of IL may be adsorbed by Na-MMT in solution with high $\mathrm{pH}$ value.

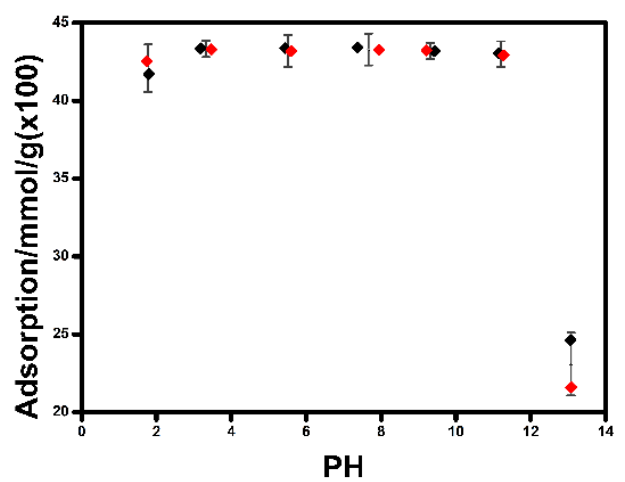

Figure 4. The adsorption of IL on sodium montmorillonite (Na-MMT) Na-MMT at different solution $\mathrm{pH}$.

\section{5. $X R D$}

X-ray diffraction $(X R D)$ was used to measure $\mathrm{d}_{001}$-spacing values of Na-MMT, which is dependent on the adsorbed exchangeable cation. Figure 5 shows the XRD patterns of modified Na-MMTs with different concentrations of IL, modified Na-MMTs at different solution $\mathrm{pH}$ and a different time. The raw Na-MMT was also measured for comparison. The $\mathrm{d}_{001}$-spacing of raw Na-MMT was $12.3 \AA$ (as shown in Figure 5a), similar to the value as reported in many works of literature [23,24]. A progressive shift to $14.0 \AA$ could be observed at IL concentration of $100 \mathrm{mg} / \mathrm{L}$. However, when the concentration of IL increased to $1000 \mathrm{mg} / \mathrm{L}$, the $\mathrm{d}_{001}$-spacing of the Na-MMT decreased to $12.7 \AA$. When the concentrations of IL further increased to $2000 \mathrm{mg} / \mathrm{L}$ and $5000 \mathrm{mg} / \mathrm{L}$, the $\mathrm{d}_{001}$-spacing of Na-MMTs remained stable of $13.3 \AA$. The results show that the $\mathrm{d}_{001}$-spacing of Na-MMT was not only 
dependent on the adsorption amount of IL but the arrangement of the interacting cationic group in the interlayer of Na-MMT. The different $\mathrm{d}_{001}$-spacing of Na-MMTs adsorbed with different amounts of IL may be induced by the different configuration of the interacting cationic group in the interlayer of Na-MMTs. The $d_{001}$-spacing of raw Na-MMT with one layer of water is $12.3 \AA$. The interlayer distance can be obtained by subtracting the thickness of the dehydrated Na-MMT layer (9.6 $)$ [22] from the observed d-spacing of the modified Na-MMT with IL. But the height of the imidazole group with alkyl chains was about $3.3 \AA$ [25]. Maybe the cationic group of the IL adopts vertical orientation which leads to larger $\mathrm{d}_{001}$-spacing of the modified Na-MMT with a lower concentration of the IL $(100 \mathrm{mg} / \mathrm{L})$. When increasing the concentration of the IL, the cationic group of the IL adopts lying parallel orientation, which leads to smaller $\mathrm{d}_{001}$-spacing of the modified Na-MMT, similar to that reported in the literature [25].

The $\mathrm{d}_{001}$-spacing of the modified Na-MMTs as the initial concentration of IL was $1000 \mathrm{mg} / \mathrm{L}$ varied with different time and different $\mathrm{pH}$ (as shown in Figures $5 \mathrm{~b}$ and $5 \mathrm{c}$ ), suggesting that the $\mathrm{d}_{001}$-spacing of Na-MMT should be not only dependent on the adsorption amount of IL but also the adsorption time and the $\mathrm{pH}$ value of the solution. The adsorption behavior is dynamic during the adsorption process even if the adsorption reaches equilibrium. The orientation adopted by the adsorbed cation group of IL at a near constant adsorption amount of $98.0 \mathrm{mg} / \mathrm{g}$ may vary with the different adsorption time or different solution $\mathrm{pH}$. The adsorbed cations of IL may adopt a tilt orientation at one time or solution $\mathrm{pH}$ and at another time or solution $\mathrm{pH}$ it may adopt vertical orientation in the interlayer of Na-MMT, which is different from that reported in other literature [5].
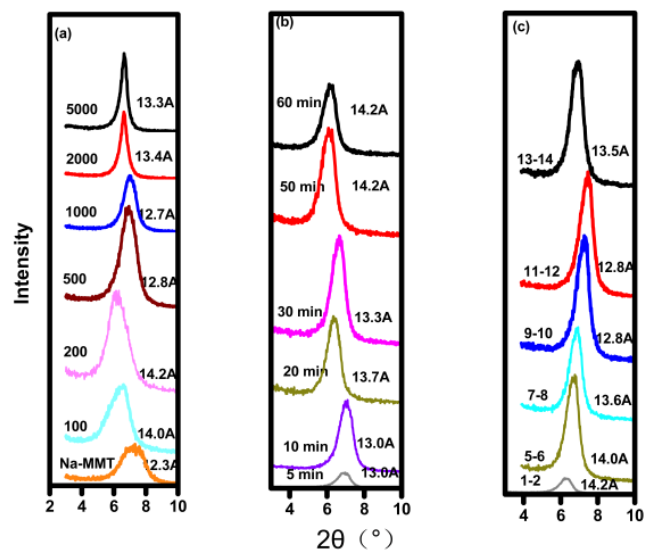

Figure 5. (a) X-ray diffraction(XRD) XRD patterns of raw Na-MMT and Na-MMT modified with different concentrations of IL; (b) XRD patterns of Na-MMT modified with $1000 \mathrm{mg} / \mathrm{L}$ IL solution for a different time; (c) XRD patterns of Na-MMT modified with $1000 \mathrm{mg} / \mathrm{L}$ IL solution at different solution $\mathrm{pH}$.

\subsection{FT-IR}

The chemical composition of materials can be measured qualitatively through fourier transform infrared (FT-IR) analyses. Figure 6 shows the FT-IR spectra of IL, raw Na-MMT and Na-MMTs modified with IL. The adsorption peaks of Na-MMT in the range of $3440-3624 \mathrm{~cm}^{-1}$ and $1640 \mathrm{~cm}^{-1}$ were ascribed to $\mathrm{O}-\mathrm{H}$ stretching and bending vibration band, respectively, which was also reported in other literature $[23,24]$. Compared with raw Na-MMT, the characteristic absorption peaks of IL could be observed in the FTIR spectrum of the modified Na-MMTs. For the modified Na-MMTs, the characteristic peaks at 3320 to $2850 \mathrm{~cm}^{-1}$ correspond to C-H absorptions of the alkyl group of IL. And the characteristic peaks of the imidazolium group could be observed at 1635 and $1580 \mathrm{~cm}^{-1}$, which is resulted from the $\mathrm{C}=\mathrm{N}$ and $\mathrm{C}=\mathrm{C}$ frame vibration. These results indicated that the cationic group of IL had successfully intercalated into the Na-MMT interlayer, similar to the exchangeable cation adsorption of organic compounds [26-28]. 


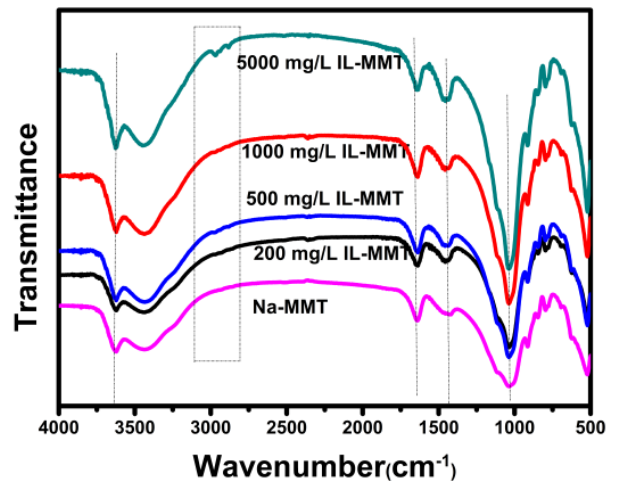

Figure 6. Fourier transform infrared(FTIR)spectra of IL, raw Na-MMT and Na-MMT modified with $1000 \mathrm{mg} / \mathrm{L}$ IL solution.

\subsection{TGA}

Figure 7 shows the thermogravimetric analyzer (TGA) patterns of IL, raw Na-MMT and the modified Na-MMTs with different concentrations of IL. As shown in Figure 7a, raw Na-MMT lost its weight at approximately $100{ }^{\circ} \mathrm{C}$, due to the loss of free water in the interlayer of Na-MMT. When the concentrations of IL were $2000 \mathrm{mg} / \mathrm{L}$ and $5000 \mathrm{mg} / \mathrm{L}$, the thermal degradation temperatures of the corresponding Na-MMTs adsorbed with $0.70 \mathrm{mmol} / \mathrm{g}$ and $0.686 \mathrm{mmol} / \mathrm{g}$ IL were about $400{ }^{\circ} \mathrm{C}$ and $350^{\circ} \mathrm{C}$, respectively. However, when the concentration of IL decreases to $1000 \mathrm{mg} / \mathrm{L}$, the thermal degradation temperature of the corresponding Na-MMT adsorbed with $0.43 \mathrm{mmol} / \mathrm{g}$ IL was about $500{ }^{\circ} \mathrm{C}$. When the concentration of IL further decreased, the thermal degradation temperature of the corresponding Na-MMT adsorbed with a lower amount of IL was beyond $500{ }^{\circ} \mathrm{C}$. These results confirmed that the thermal stability of Na-MMTs adsorbed with lower IL amounts were better than that of Na-MMTs with higher IL amounts, probably due to chemical adsorption of Na-MMTs with lower IL amounts and physical adsorption of Na-MMTs with higher IL amounts [21-23]. Meanwhile, Na-MMT adsorbed with IL had better thermal stability than Na-MMT adsorbed with a quaternary amine, the degradation temperature of the latter was reported to be about $180{ }^{\circ} \mathrm{C}$ [11].

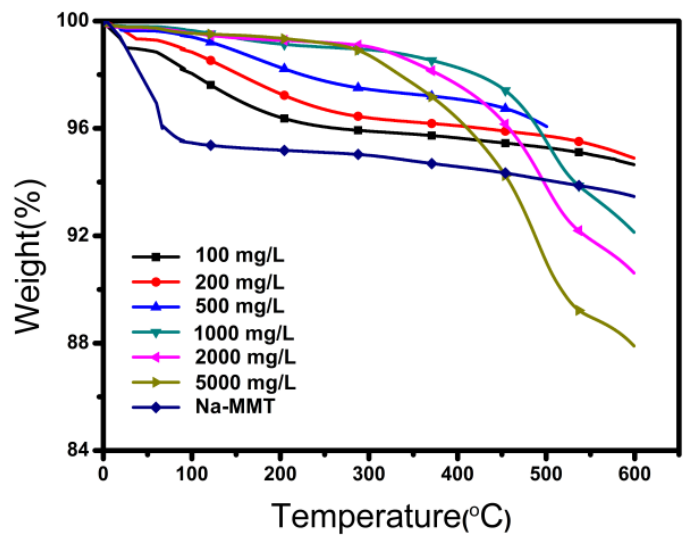

Figure 7. Thermogravimetric analyzer (TGA)TG patterns of raw Na-MMT and Na-MMT adsorbed with different concentrations of IL.

\subsection{Contact Angle Measurement}

The contact angle is used to characterize the wettability of a material surface. Higher contact angles indicate that the material is more lipophilic than hydrophilic. Figure 8 showed the contact angles of raw Na-MMT and modified Na-MMT with different concentrations of IL. The contact angle of raw Na-MMT was $20^{\circ}$, equal to the reported value. The Na-MMT modified with $1000 \mathrm{mg} / \mathrm{L}$ of 
IL showed a slightly higher contact angle (ca.40 $)$, suggesting that the modified Na-MMT tend to be more lipophilic. When IL concentrations increased to $2000 \mathrm{mg} / \mathrm{L}$ and $5000 \mathrm{mg} / \mathrm{L}$, the contact angles of the modified Na-MMT were $45^{\circ}$ and $50^{\circ}$, respectively, much higher than that of raw Na-MMT. These results show that the insertion of IL into the interlayer of Na-MMT could change the wettability of Na-MMT and the modified Na-MMT tends to be more lipophilic. The cation group of IL with alkyl chain exchanged with the $\mathrm{Na}^{+}$of Na-MMT, which enhanced the lipophilicity of the Na-MMT.

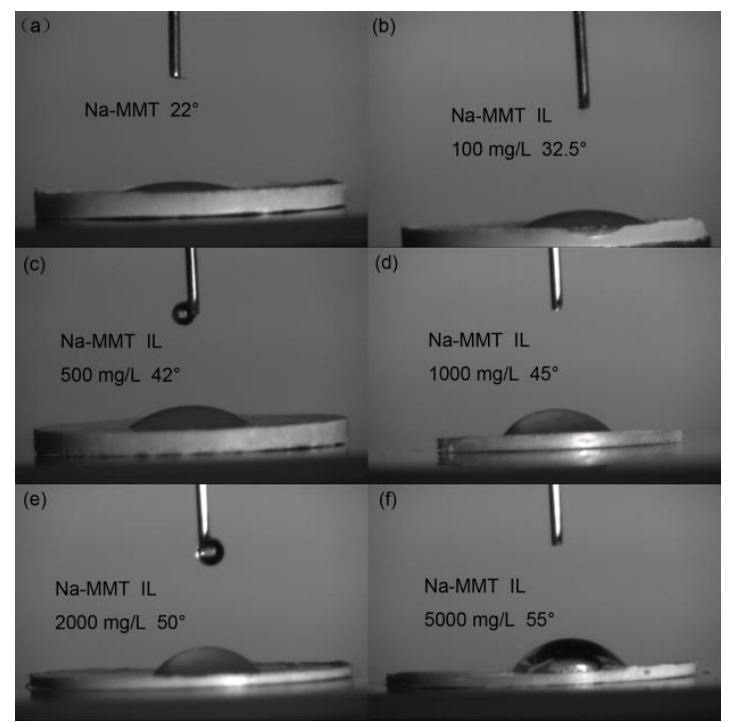

Figure 8. Contact angles of raw Na-MMT and modified Na-MMT with different concentrations of IL.

\subsection{Atomic Arrangement of IL in the Interlayer of Na-MMT}

Previous studies showed that the configuration of an intercalated cation in the Na-MMT interlayer was largely dependent on the concentration of intercalated molecules [25]. In this study, the $\mathrm{d}_{001}$-spacing of raw Na-MMT with one layer of water is $12.3 \AA$. The interlayer distance $(4.2 \AA)$ can be obtained by subtracting the thickness of dehydrated Na-MMT layer (9.6 $\AA$ ) [22] from the observed d-spacing of the Na-MMT modified with IL of $100 \mathrm{mg} / \mathrm{L}(14.0 \AA)$. However, the ionic height of imidazole group with alkyl chain was about $3.3 \AA$ [25]. The result suggested that a bilayer formation of the cationic group should occur in the interlayer of the modified Na-MMT. The cationic group of IL may adopt a special orientation in the interlayer and its orientation may be parallel or tilting.

A molecular simulation was performed to determine the atomic arrangement of IL and the locations of two N atoms (Figure 9). The results show that the intercalated cation groups of IL adopted a bilayer formation, which further confirmed the previous analysis. But one layer of the intercalated cation groups adopted parallel orientation and another adopted vertical state in the interlayer of Na-MMT (Figure 9a). The distance from the basal plane of interlayer space to the $\mathrm{N}$ on the shorter alkyl chain is $2-3 \AA$ or $14-16 \AA$, and the distance from the basal plane of interlayer space to another $\mathrm{N}$ on the longer alkyl chain is $6-8 \AA$ or $10-12 \AA$. The two $N$ atoms in the imidazole ring can be found to have two positions in the interlayer of Na-MMT: one is in the middle of the interlayer space while the other is closed to the basal plane of the interlayer space. 

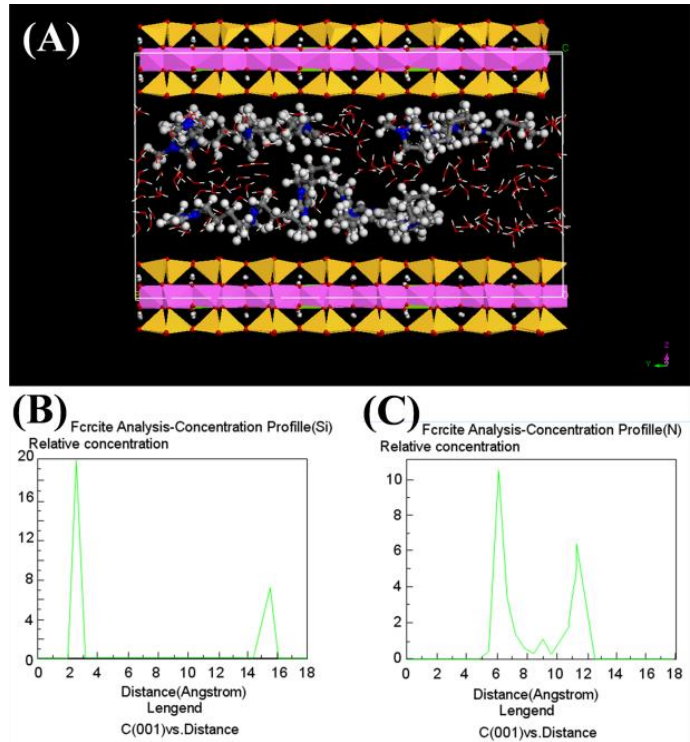

Figure 9. (A) Molecular simulation of IL conformation in the interlayer of Na-MMT; $(\mathbf{B}, \mathbf{C})$ the possible locations of two different $\mathrm{N}$ in the imidazole ring. In (A) blue is $\mathrm{N}$, dark gray is $\mathrm{C}$, and light gray is $\mathrm{H}$.

\section{Experimental Work}

1-butyl-3-methylimidazolium tetrafluoroborate (CAS\#: 174501-65-6), abbreviated as IL, was provided by Chenjie Chemical Co. Ltd., Shanghai China. It has a molecular weight of 226.02 $\mathrm{g} / \mathrm{mol}$ and its purity was $99 \%$. Its water solubility is $2-4 \mathrm{~g} / \mathrm{mL}$ and its $\mathrm{pH}$ is 5 at $20^{\circ} \mathrm{C}$. Its formula is shown in Figure 10. Na-montmorillonite (Na-MMT) was obtained from Zhejiang Fenghong new material company, Huzhou, Zhejiang China. The density and CEC of Na-MMT are $2.70 \mathrm{~g} / \mathrm{cm}^{3}$ and 0.9 $\mathrm{mmol} / \mathrm{g}$, respectively. It is composed of $95 \%$ smectite, $4.0 \%$ quartz and $1 \%$ mica+gypsum+feldspar and its formulas is written as $\left.\mathrm{Ca}_{0.12} \mathrm{Na}_{0.32} \mathrm{~K}_{0.05}\right)\left[\mathrm{Al}_{3.01} \mathrm{Fe}(\mathrm{III})_{0.41} \mathrm{Mg}_{0.54}\right]\left[\mathrm{S}_{\mathrm{i} 7.98} \mathrm{Al}_{0.02}\right] \mathrm{O}_{20}(\mathrm{OH})_{4}$.

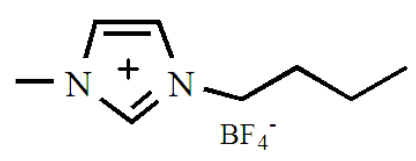

Figure 10. The IL formula.

Na-MMTs modified with different initial concentrations of IL varying from 100 to $5000 \mathrm{mg} / \mathrm{L}$ were prepared for the adsorption isotherm study. Na-MMT $(0.2 \mathrm{~g})$ was dispersed in $20 \mathrm{~mL}$ of IL solution and the suspensions were shaken for $24 \mathrm{~h}$ at $30^{\circ} \mathrm{C}$. After being centrifuged at $7600 \mathrm{rpm}$ for $30 \mathrm{~min}$, the suspensions were filtered through $0.45 \mu \mathrm{m}$ syringe filters, and then the filter liquor was analyzed for the concentrations of IL and the desorbed exchangeable cations. Each precipitate was washed with distilled water at least three times until no IL could be detected in the supernatant by a UV-Visible spectrophotometer (Model T6, China). The clay samples were obtained by drying the precipitates at $105^{\circ} \mathrm{C}$ for $24 \mathrm{~h}$ in an oven before measurement. The IL concentration was fixed at $1000 \mathrm{mg} / \mathrm{L}$ for the study of adsorption kinetics and $\mathrm{pH}$ effects on the adsorption of IL by Na-MMT. The $\mathrm{pH}$ value of the Na-MMT/IL dispersion was adjusted to about 2, 3, 5, 7, 9, 11 and 13 with $\mathrm{HCl}$ or $\mathrm{KOH}$.

The IL concentrations were measured with UV-Vis spectrophotometer at the wavelength of $211 \mathrm{~nm}$ [29], corresponding to its maximum absorbance wavelength. The calibration curve was obtained by measuring the absorbance values of the IL solution with varying concentration (10, 20, 30, 40, 50 and $60 \mathrm{mg} / \mathrm{L}$ ) and the regression coefficient was greater than 0.999 (Figure 11). The 
adsorbed amount of IL can be calculated by the difference between the final and initial IL concentration. The equation is as follows:

$$
\begin{aligned}
& \mathrm{q}_{t}=\frac{\left(C_{0}-C_{t}\right) V}{M} \\
& \mathrm{q}_{\mathrm{e}}=\frac{\left(C_{0}-C_{e}\right) V}{M}
\end{aligned}
$$

where $\mathrm{q}_{\mathrm{t}}$ and $\mathrm{q}_{\mathrm{e}}$ are the corresponding adsorbed amount of IL by Na-MMT at $\mathrm{t}$ and equilibrium time, respectively $(\mathrm{mmol} / \mathrm{g}) . \mathrm{C}_{\mathrm{t}}$ and $\mathrm{C}_{\mathrm{e}}$ are the corresponding concentration of the IL at $\mathrm{t}$ and equilibrium time, respectively $(\mathrm{mmol} / \mathrm{L}) . \mathrm{C}_{0}$ is the initial concentration of the $\mathrm{IL}(\mathrm{mmol} / \mathrm{L}), \mathrm{V}$ is the volume of IL solution (L), $\mathrm{M}$ is the weight of adsorbent $(\mathrm{g})$.

Each test was conducted three times, and the error is less than $5 \%$.
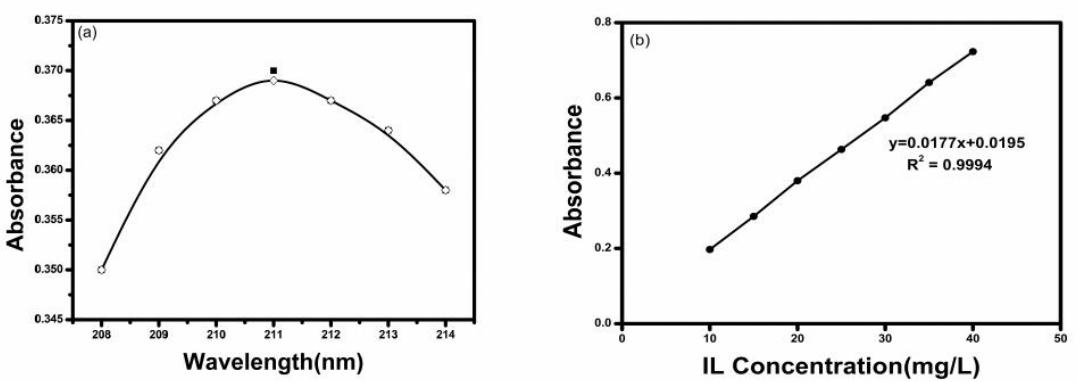

Figure 11. (a) the absorbance of the IL at different adsorption wavelength; (b) absorbance at $211 \mathrm{~nm}$ for IL solution with different concentrations and the fitted calibration curve.

The desorbed exchangeable cations were measured by atomic adsorption on a AAnalyst-100 Atomic Absorption Spectrometer (Perkin Elmer Corporation, Waltham, MA, USA). Seven standard solutions with concentrations from 0.2 to $3.0 \mathrm{mg} / \mathrm{L}$ for $\mathrm{K}^{+}, \mathrm{Na}^{+}$, and $\mathrm{Mg}^{2+}$, and from 1.0 to $25.0 \mathrm{mg} / \mathrm{L}$ for $\mathrm{Ca}^{2+}$ were used to make the calibration curve. The detection limit was $0.006,0.01,0.06$, and 0.4 $\mathrm{mg} / \mathrm{L}$ for $\mathrm{Na}^{+}, \mathrm{K}^{+}, \mathrm{Mg}^{2+}$ and $\mathrm{Ca}^{2+}$ with detection wavelengths at 589.0, 766.5, 285.2, and 422.7 $\mathrm{nm}$, respectively.

The clay samples were scanned using a Ultima X-ray diffractometer (XRD) (Rigaku Corporation, Tokyo, Japan) with $\mathrm{Cu}-\mathrm{K} \alpha$ radiation $(40 \mathrm{kV}, 100 \mathrm{~mA})$. The $\mathrm{XRD}$ patterns were collected from $2^{\circ}$ to $50^{\circ}$ at a $2 \%$ min scanning rate. Fourier transform infrared (FT-IR) spectra of raw Na-MMT, IL and the modified Na-MMT were obtained by a NEXUS-650 FT-IR spectrometer (Nicolet corporation, Madison, WI, USA). The thermal stability of the clay samples was measured by the SDT Q600 thermogravimetric analyzer (TGA) (TA instruments, New Castle, DE, USA) from room temperature to $600^{\circ} \mathrm{C}$, operating at a heating rate of $10^{\circ} \mathrm{C} / \mathrm{min}$ in an air atmosphere. The contact angle was tested on a JC 200D contact angle instrument (shanghai zhongchen Digital Technology Co.,LTD, Shanghai, China) with deionized water. The testing samples were prepared according to a method in the literature [30]. A molecular simulation was performed to investigate the atomic arrangement of IL in the interlayer of Na-MMT via the module Forcite of materials studio software 5.0.

\section{Conclusions}

The adsorption of IL by Na-MMT was rapid at a fast rate. The adsorption kinetics of IL by Na-MMT followed the pseudo-second-order model very well, and its adsorption equilibrium amount was $0.43 \mathrm{mmol} / \mathrm{g}$, lower than the CEC value of $0.90 \mathrm{mmol} / \mathrm{g}$. The adsorption of IL by Na-MMT reached the maximum adsorption amount of $0.70 \mathrm{mmol} / \mathrm{g}$ at the IL concentration of $2000 \mathrm{mg} / \mathrm{L}$, but the highest adsorption rate occurred when the IL concentration was $1000 \mathrm{mg} / \mathrm{L}$. Cation exchange was the dominating adsorption mechanism and the cation group of IL could not completely substitute the exchangeable cation of Na-MMT. XRD and FTIR analysis indicated that the cation group of IL interacted into the interlayer of Na-MMT, which changed the wettability and improved the thermal 
stability of Na-MMT. A bilayer formation of the cationic group should occur in the interlayer of the modified Na-MMT, the configuration of IL and the thermal stability of the modified Na-MMTs were dependent on the IL concentrations.

Author Contributions: J.P.: data collection and analysis, writing; X.X.: data collection and analysis; B.X.: substantial contributions to the conception of the work and data analysis;Z.W.: data collection and figures; Z.L.: study design, literature search and writing.

Funding: This research was funded by National Key R and D Program of China (No. 2016YFE0202200), the National Natural Science Foundation of China (No. 51204150), Natural Science Foundation of Beijing (No. 3123042).

Conflicts of Interest: The authors declare no conflict of interest.

\section{References}

1. Caenn, R.; Darley, H.C.H. Composition and Properties of Drilling and Composition Fluids, 6th ed.; Gulf Professional Publishing: Waltham, MA, USA, 2011; Chapter 4; pp. 144-150.

2. Framer, V.C. The infrared Spectra of Minerals, Mineralogical Society: London, Great Britain \& Ireland. 1974.

3. Xue, Q.L.; Leung, H.; Huang, L.L.; Zhang, R.; Liu, B.L.; Wang, J.; Li, L.X. Modeling of torsional oscillation of drilling strilling dynamics. Nonlinear Dyn. 2019, 1-17.

4. Emmerich, K.; Madsen, F.T.; Kahr, G. Dehydroxylation behavior of heat-treated and steam-treated homoionic cis-vacant montmorillonites. Clays Clay Miner. 1999, 47, 91-604. [CrossRef]

5. Lv, G.C.; Liu, L.; Li, Z.H.; Liao, L.B.; Liu, M.T. Probing the interactions between chlopheniramine and 2:1 phyllosilicates. J. Colloid Interface Sci. 2012, 374, 218-225. [CrossRef] [PubMed]

6. Jung, Y.; Son, Y.H.; Lee, J.K.; Phuoc, T.X.; Soong, Y.; Chyu, M.K. Rheological behavior of clay nanoparticle hybrid-added bentonite suspensions: Specific role of hybrid additives on the gelation of clay-based fluids. ACS Appl. Mater. Interfaces 2011, 3, 3515-3522. [CrossRef]

7. Chiem, L.T.; Huynh, L.; Ralston, J.; Beattie, D.A. An in situ ATR-FTIR study of polyacrylamide adsorption at the talc surface. J. Colloid Interface Sci. 2006, 297, 54-61. [CrossRef] [PubMed]

8. Van Damme, H.; Crespin, M.; Cruz, M.I.; Fripiat, J.J. Adsorption of safranine by $\mathrm{Na}^{+}, \mathrm{Ni}^{+}, \mathrm{and} \mathrm{Fe}^{3+}$ montmorillonites. Clays Clay Miner. 1977, 25, 19-25. [CrossRef]

9. Zhuang, G.Z.; Zhang, Z.P.; Fu, M.; Ye, X.; Liao, L.B. Comparative study on the use of cationic-nonionicorgano-montmorillonite in oil-based drilling fluids. Appl. Clay Sci. 2015, 116, 257-262. [CrossRef]

10. Abdo, J.; Haneef, M.D. Clay nanoparticles modified drilling fluids for drilling of deep hydrocarbon wells. Appl. Clay Sci. 2013, 86, 76-82. [CrossRef]

11. Xie, W.; Gao, Z.; Pan, W.P.; Hunter, D.; Singh, A.; Vaia, R. Thermal degradation chemistry of alkyl quaternary ammonium montmorillonite. Chem. Mater. 2001, 13, 2979-2990. [CrossRef]

12. Pinkert, A.; Marsh, K.N.; Pang, S.S.; Staiger, M.P. Ionic liquids and their interaction with cellulose. Chem. Rev. 2009, 109, 6712-6728. [CrossRef]

13. Singh, M.P.; Singh, R.K.; Chandra, S. Ionic liquids confined in porous matrices: Physicochemical properties and applications. Prog. Mater Sci. 2014, 64, 73-120. [CrossRef]

14. Macfarlane, D.R.; Tachikawa, N.; Forsyth, M.; Pringle, J.M.; Howlett, P.C. Energy applications of ironic liquids. Energy Environ. Sci. 2014, 7, 232-250. [CrossRef]

15. Lu, J.; Yan, F.; Texter, J. Advanced application of Ionic liquids in polymer science. Polym. Sci. 2009, 34, 431-448.

16. Neung, H.K.; Sanjay, V.M.; Marino, X. Modification of cationic nanoclays with ionic liquids. Microporous Mesoporous Mater. 2006, 96, 29-35.

17. Harris, K.R.; Kanakubo, M.; Woolf, L.A. Temperature and pressure dependence of the viscosity of the ionic liquid 1-Butyl-3-methylimidazolium Tetrafluoroborate: viscosity and density relationships in ionic liquids. J. Chem. Eng. Data 2007, 52, 2425-2430. [CrossRef]

18. Livi, S.; Duchet-Rumeau, J.; Pham, T.N.; Gérard, J.F. A comparative study on different ionic liquids used as surfactants: Effect on thermal and mechanical properties of high-density polyethylene nanocomposites. J. Colloid Interface Sci. 2010, 349, 424-433. 
19. Reinert, L.; Batouche, K.; Lévêque, J.M.; Muller, F.; Bény, J.M.; Brahim, K.; Kebabi, B.; Duclaux, L. Adsorption of imidazolium and pyridinium ionic liquids onto montmorillonite: Characterisation and thermodynamic calculations. Chem. Eng. J. 2012, 209, 13-19. [CrossRef]

20. Luo, Z.H.; Pei, J.J.; Wang, L.X. Influence of an ionic liquid on rheological and filtration properties of water-based drilling fluids at high temperatures. Appl. Clay Sci. 2017, 136, 96-102. [CrossRef]

21. Zhou, L.; Chen, H.; Jiang, X.; Lu, F.; Zhou, Y.; Yin, W.; Ji, X. Modification of montmorillonite surfaces using a novel class of cationic Gemini surfactants. J. Colloid Interface Sci. 2009, 332, 16-21. [CrossRef]

22. Chapeaux, A.; Simoni, L.D.; Stadtherr, M.A.; Brenecke, J.F. Liquid phase behavior of ionic liquids with water and 1-octanol and modeling of 1-octanol/water partition coefficient. J. Chem. Eng. Data 2007, 52, 2462-2467. [CrossRef]

23. Ding, Y.S.; Wang, S.S.; Zhan, M.; Wang, Z.G. Physico chemical adsorption and aggregative structures of the organic cation $\left[\mathrm{C}_{18} \mathrm{mim}\right]^{+}$in the layer of montmorillonite. Acta Phys. Chem. Sin. 2006, 22, 548-551. [CrossRef]

24. Goswami, S.K.; Ghosh, S.; Mathias, L.J. Thermally stable organically modified layered silicates based on alkyl imidazolium salts. J. Colloid Interface Sci. 2012, 368, 366-371. [CrossRef]

25. Fredlake, C.P.; Crosthwaite, J.M.; Hert, D.G.; Aki, S.N.V.K.; Brennecke, J.F. Thermophysical properties of imidazolium-based ionic liquids. J. Chem. Eng. Data 2004, 49, 954-964. [CrossRef]

26. Belbel, A.; Kharroubi, M.; Janot, J.M.; Abdessamad, M.; Haouzi, A.; Lefkaier, I.K.; Balme, S. Preparation and characterization of homoionic montmorillonite modified with ionic liquid: Application in dye adsorption. Colloids Surf. A 2018, 558, 219-227. [CrossRef]

27. Takahashi, C.; Takashi, S.; Masayoshi, F. Study on intercalation of ionic liquid into montmorillonite and its property evaluation. Mater. Chem. Phys. 2012, 135, 681-686. [CrossRef]

28. Mahmoud, M.E.; Al-Bishri, H.M. Supported hydrophobic ionic liquid on nano-silica for adsorption of lead. Chem. Eng. J. 2011, 166, 157-167. [CrossRef]

29. Beaulieu, J.J.; Tank, J.L.; Kopacz, M. Sorption of imidazolium-based ionic liquids to aquatic sediments. Chemophere 2008, 70, 1320-1328. [CrossRef]

30. Bronislaw, J.; Tomasz, B. Components of surface free energy of some clay minerals. Clay Clay Miner. 1988, 36, 243-248.

Sample Availability: Samples of the compounds are not available from the authors.

(C) 2019 by the authors. Licensee MDPI, Basel, Switzerland. This article is an open access article distributed under the terms and conditions of the Creative Commons Attribution (CC BY) license (http://creativecommons.org/licenses/by/4.0/). 